\title{
Hypermethylation of the large tumor suppressor genes in Japanese lung cancer
}

\author{
HIDEFUMI SASAKI, YU HIKOSAKA, OSAMU KAWANO, \\ MOTOKI YANO and YOSHITAKA FUJII \\ Department of Oncology, Immunology and Surgery, Nagoya City \\ University Medical School, Nagoya 467-8601, Japan
}

Received June 12, 2009; Accepted September 3, 2009

DOI: 10.3892/ol_00000054

\begin{abstract}
Large tumor suppressor (LATS) 1 and 2 are tumor suppressor genes implicated in the regulation of the cell cycle. The methylation statuses of the promoter regions of these genes were studied in Japanese lung cancers. The methylation statuses of the promoter regions of LATS1 and LATS2 were investigated by methylation-specific PCR. The findings were compared to clinicopathological features of lung cancer. Methylationspecific PCR showed that the LATS1 promoter region was hypermethylated in 95 out of $119(79.8 \%)$ lung cancers. The methylation status of LATS1 was significantly associated with squamous histology $(\mathrm{p}=0.0267)$ and smoking status (never smoker vs. smoker; $\mathrm{p}=0.0399)$. LATS1-ummethylated patients harbored more EGFR mutations $(\mathrm{p}=0.0143)$. The LATS2 promoter region was hypermethylated in 160 out of 203 (78.8\%) lung cancers. However, the methylation status had no association with the clinicopathological characteristics of the lung cancers cases. Both the LATS1 and LATS2 methylation statuses did not correlate with survival of lung cancer patients. Thus, the EGFR methylation status of the LATS genes has limited value in Japanese lung cancers.
\end{abstract}

\section{Introduction}

Large tumor suppressor (LATS), which encodes a putative serine/threonine kinase, has been identified as a tumor suppressor gene in Drosophila $(1,2)$. Deterioration of the LATS gene function results in promotion of cell proliferation and tumor formation in Drosophila (2). Two mammalian homologues of the Drosophila LATS, LATS1 and LATS2 have been identified. LATS1-deficient mice developed soft tissue sarcomas or ovarian stromal cell tumors, suggesting that LATS1 is a tumor suppressor gene (3). Overexpression of

Correspondence to: Dr Hidefumi Sasaki, Department of Oncology, Immunology and Surgery, Nagoya City University Medical School, 1 Kawasumi, Mizuho-cho, Mizuho-ku, Nagoya 467-8601, Japan

E-mail: hisasaki@med.nagoya-cu.ac.jp

Key words: hypermethylation, large tumor suppressor gene, lung cancer
LATS1 causes G2-M arrest through the inhibition of CDC2 kinase activity in vitro (4). Furthermore, overexpression of LATS1 significantly suppresses tumorigenicity in vivo by inducing apoptosis $(4,5)$.

LATS2 overexpression results in cell cycle arrest in the $\mathrm{G} 2 / \mathrm{M}$ phase via inhibition of Cdc2-cyclin B kinase activity leading eventually to apoptosis (6), inhibition of G1/S transition via down-regulation of $\mathrm{Cdk} 2$-cyclin $\mathrm{E}$ kinase activity (7), or apoptosis via down-regulation of Bcl-2 and $\mathrm{Bcl}-\mathrm{xL}$ (8). LATS2 binds to Mdm2 and inhibits its E3 ubiquitin ligase activity, resulting in the stabilization of p53 (9).

DNA methylation is an essential mechanism for the regulation of genes which contain a defined $\mathrm{CpG}$ island, and LATS2 hypermethylation has been recently associated with an aggressive phenotype in breast cancers (10). Down-regulation of the LATS2 gene is associated with poor prognosis in acute lymphoblastic leukemia (11). More recently, LATS2 gene tumorspecific mutations and down-regulation have been reported in non-small cell carcinoma (12). These findings have led us to analyze the potential role of the promoter hypermethylation of the LATS1 and 2 genes in non-small cell lung cancer (NSCLC) patients. In this study, the methylation statuses of the promoter regions of these genes were studied in Japanese lung cancers. The methylation statuses of the promoter regions of LATS1 and 2 were investigated by methylation-specific PCR. The findings were compared to the clinicopathological features of the lung cancer cases.

\section{Patients and methods}

Patients. The study group included lung cancer patients who had undergone surgery at the Department of Surgery II, Nagoya City University Medical School. The lung tumors were classified according to the general rule for clinical and pathological recording of lung cancer in Japan (13). All tumor samples were immediately frozen and stored at $-80^{\circ} \mathrm{C}$ until assayed. Since Strazisar et al revealed that LATS 2 mutations were predominantly found in the squamous cell histotype of lung cancer while no mutations were found in adenocarcinoma (12), we mainly focused on squamous cell carcinoma for the LATS2 sequencing study. The clinical and pathological characteristics of the 178 lung cancer patients for the LATS2 sequencing analysis were as follows: 159 (89.3\%) were male 
Table I. Clinicopathological data of 119 lung cancer patients.

\begin{tabular}{|c|c|c|c|}
\hline \multirow[b]{2}{*}{ Factors } & \multicolumn{2}{|c|}{ LATS1 gene status } & \multirow[b]{2}{*}{ P-value } \\
\hline & Methylated patients & Unmethylated patients & \\
\hline Mean age (years) & $64.5 \pm 8.9$ & $66.3 \pm 13.3$ & 0.2211 \\
\hline \multicolumn{4}{|l|}{ Stage } \\
\hline I & $38(40.0 \%)$ & $11(45.8 \%)$ & \multirow[t]{2}{*}{0.6470} \\
\hline II-IV & $57(60.0 \%)$ & $13(54.2 \%)$ & \\
\hline \multicolumn{4}{|c|}{ Lymph node metastasis } \\
\hline No & $54(56.8 \%)$ & $16(66.7 \%)$ & \multirow[t]{2}{*}{0.4880} \\
\hline $\mathrm{N}^{+}$ & $41(43.2 \%)$ & $8(33.3 \%)$ & \\
\hline \multicolumn{4}{|l|}{ Smoking } \\
\hline Never smoker & $22(23.2 \%)$ & $11(45.8 \%)$ & \multirow[t]{2}{*}{0.0399} \\
\hline Smoker & $73(76.8 \%)$ & $13(54.2 \%)$ & \\
\hline \multicolumn{4}{|l|}{ EGFR mutation } \\
\hline Wild-type & $77(81.1 \%)$ & $13(54.2 \%)$ & \multirow[t]{2}{*}{0.0143} \\
\hline Mutation & $18(18.9 \%)$ & $11(45.8 \%)$ & \\
\hline \multicolumn{4}{|c|}{ Pathological subtypes } \\
\hline SCC & $36(37.9 \%)$ & $3(12.5 \%)$ & \multirow[t]{2}{*}{0.0267} \\
\hline Non-SCC & $59(62.1 \%)$ & $21(87.5 \%)$ & \\
\hline \multicolumn{4}{|l|}{ Age } \\
\hline$\leq 65$ & $39(41.1 \%)$ & $9(37.5 \%)$ & \multirow[t]{2}{*}{0.8190} \\
\hline$>65$ & $56(58.9 \%)$ & $15(62.5 \%)$ & \\
\hline \multicolumn{4}{|l|}{ Gender } \\
\hline Male & $75(78.9 \%)$ & $15(62.5 \%)$ & \multirow[t]{2}{*}{0.1872} \\
\hline Female & $20(21.1 \%)$ & $9(37.5 \%)$ & \\
\hline
\end{tabular}

$\mathrm{N}^{+}$, lymph node metastasis positive; SCC, squamous cell carcinoma.

and 19 were female. One hundred and sixteen (65.2\%) patients were diagnosed as squamous cell carcinomas, 42 were adenocarcinomas and 17 were adenosquamous cell carcinomas. One hundred and sixty-five $(92.7 \%)$ were smokers and 13 were non-smokers. The clinicopathological characteristics of the lung cancer patients in the methylation analyses for LATS1 and 2 are listed in Tables I and II, respectively. The samples from these patients were previously sequenced for EGFR (13-16).

PCR assays for LATS2 mutations. Total RNA was extracted from lung cancer tissues using the Isogen Kit (Nippon Gene, Tokyo, Japan), according to the manufacturer's instructions. The RNA concentration was determined using a spectrophotometer and adjusted to a concentration of $200 \mathrm{ng} / \mathrm{ml}$. Approximately 10 cases were excluded for each assay, since the tumor cells were too few to sufficiently extract tumor RNA. RNA $(1 \mu \mathrm{g})$ was reverse transcribed by Superscript II enzyme (Gibco BRL, Gaithersburg, MD, USA) with $0.5 \mu \mathrm{g}$ oligo (dT) $)_{12-16}$ (Amersham Pharmacia Biotech Inc., Piscataway, NJ, USA). The reaction mixture was incubated at $42^{\circ} \mathrm{C}$ for $50 \mathrm{~min}$ and then at $72^{\circ} \mathrm{C}$ for $15 \mathrm{~min}$. We then used $1 \mu \mathrm{l}$ of each DNA for PCR analysis. The PCR reactions were performed using the LA-Taq Kit (Takara Bio Inc., Shiga, Japan) in a $25-\mu 1$ reaction volume. The primer sequences for the LATS2 gene for exon 8 (including the S1073 region) were as follows: forward primer
5-CGACCCCGTAGATGAAGAAA-3 and reverse primer 5-AGCGATGCTGAGTCCTGTT-3 (454 bp, 3448-3901). The cycling conditions were as follows: initial denaturation at $94^{\circ} \mathrm{C}$ for $5 \mathrm{~min}$, followed by 40 cycles at $94^{\circ} \mathrm{C}$ for $45 \mathrm{sec}, 60^{\circ} \mathrm{C}$ for $45 \mathrm{sec}$ and $72^{\circ} \mathrm{C}$ for $45 \mathrm{sec}$. The products were purified using the Qiagen PCR Purification Kit (Qiagen, Valencia, CA, USA). These samples were sequenced by ABI PRISM 3100 analyzer (Applied Biosystems Japan Ltd., Tokyo, Japan) and analyzed by BLAST and chromatograms by manual review.

Methylation-specific polymerase chain reaction analysis. DNA was prepared from tissue samples using the standard methods, and bisulfite modification of genomic DNA was performed using the MethylCode Bisulfite Conversion Kit (Invitrogen). Briefly, $500 \mathrm{ng}$ of genomic DNA was denatured by incubation with CT Conversion Reagent for $10 \mathrm{~min}$ at $98^{\circ} \mathrm{C}$, followed by $2.5 \mathrm{~h}$ at $68^{\circ} \mathrm{C}$ and $4^{\circ} \mathrm{C}$ for several minutes. Modified DNA was purified using a spin column and then eluted with dlution buffer.

The primer sequences for the LATS1 gene for methylated (M) sequences were as follows: forward primer 5-GGAGTT CGTTTTGTC-3 and reverse primer 5-CGACGTAATAACG AACGCCTA-3. The primer sequences for the LATS1 gene for unmethylated (U) sequences were as follows: forward primer 5-TAGGTTGGAGTGTGGTGGT-3 and reverse primer 5-CCC 
Table II. Clinicopathological data of 203 lung cancer patients.

\begin{tabular}{|c|c|c|c|}
\hline \multirow[b]{2}{*}{ Factors } & \multicolumn{2}{|c|}{ LATS2 gene status } & \multirow[b]{2}{*}{ P-value } \\
\hline & Methylated patients & Unmethylated patients & \\
\hline Mean age (years) & $66.1 \pm 8.9$ & $64.3 \pm 10.9$ & 0.4076 \\
\hline $\begin{array}{l}\text { Stage } \\
\text { I } \\
\text { II-IV }\end{array}$ & $\begin{array}{l}70(43.8 \%) \\
90(56.2 \%)\end{array}$ & $\begin{array}{l}22(51.2 \%) \\
21(48.8 \%)\end{array}$ & 0.3946 \\
\hline $\begin{array}{l}\text { Lymph node metast } \\
\text { N0 } \\
\mathrm{N}^{+}\end{array}$ & $\begin{array}{l}95(59.4 \%) \\
65(40.6 \%)\end{array}$ & $\begin{array}{l}27(62.8 \%) \\
16(37.2 \%)\end{array}$ & 0.7286 \\
\hline $\begin{array}{l}\text { Smoking } \\
\text { Never smoker } \\
\text { Smoker }\end{array}$ & $\begin{array}{r}35(21.9 \%) \\
125(78.1 \%)\end{array}$ & $\begin{array}{l}14(32.6 \%) \\
29(67.4 \%)\end{array}$ & 0.1622 \\
\hline $\begin{array}{l}\text { EGFR mutation } \\
\text { Wild-type } \\
\text { Mutation }\end{array}$ & $\begin{array}{r}126(78.8 \%) \\
34(21.2 \%)\end{array}$ & $\begin{array}{r}35(81.4 \%) \\
8(18.6 \%)\end{array}$ & 0.8332 \\
\hline $\begin{array}{l}\text { Pathological subtype } \\
\text { SCC } \\
\text { Non-SCC }\end{array}$ & $\begin{array}{l}80(50.0 \%) \\
80(50.0 \%)\end{array}$ & $\begin{array}{l}18(41.9 \%) \\
25(58.1 \%)\end{array}$ & 0.3920 \\
\hline $\begin{array}{l}\text { Age } \\
\leq 65 \\
>65\end{array}$ & $\begin{array}{l}68(42.5 \%) \\
92(57.5 \%)\end{array}$ & $\begin{array}{l}22(51.2 \%) \\
21(48.8 \%)\end{array}$ & 0.3876 \\
\hline $\begin{array}{l}\text { Gender } \\
\text { Male } \\
\text { Female }\end{array}$ & $\begin{array}{r}123(76.9 \%) \\
37(23.1 \%)\end{array}$ & $\begin{array}{l}31(72.1 \%) \\
12(27.9 \%)\end{array}$ & 0.5490 \\
\hline
\end{tabular}

$\mathrm{N}^{+}$, lymph node metastasis positive; SCC, squamous cell carcinoma.

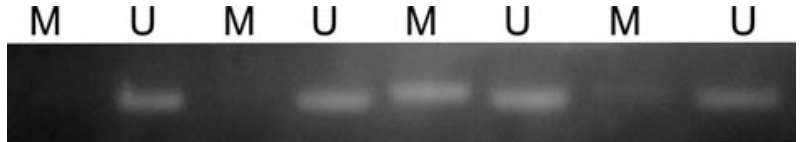

Figure 1. The results of the methylation-specific PCR analysis of LATS2 in 4 lung cancers. M, methylated; U, unmethylated.

AACATAATAACAAACACCT-3. The primer sequences for the LATS2 gene for methylated (M) sequences were as follows: forward primer 5-ATTTCGGTTTATTGTAATTTTC-3 and reverse primer 5-AACCAACATAATAAAACCCCG-3. The primer sequences for the LATS2 gene for unmethylated (U) sequences were as follows: forward primer 5-TTTGTTTTTT GGGTTTAAGT-3 and reverse primer 5-CCAACATAATA AAACCCCA-3. The cycling conditions were as follows: initial denaturation at $94^{\circ} \mathrm{C}$ for $5 \mathrm{~min}$, followed by 40 cycles at $94^{\circ} \mathrm{C}$ for $45 \mathrm{sec}, 58^{\circ} \mathrm{C}$ (LATS1 and LATS2, M) or $53^{\circ} \mathrm{C}$ (LATS1, U) or $50^{\circ} \mathrm{C}(L A T S 2, \mathrm{U})$ for $45 \mathrm{sec}$, and $72^{\circ} \mathrm{C}$ for $45 \mathrm{sec}$.

Statistical analysis. Statistical analyses were carried out using the Mann-Whitney $U$ test for unpaired samples and the Wilcoxon's signed rank test for paired samples. Linear relationships between variables were determined by means of simple linear regression. Correlation coefficients were determined by rank correlation using the Spearman's and $\chi^{2}$ tests. The overall survival of lung cancer patients was examined by the Kaplan-Meier method, and differences were examined by the log-rank test. Analysis was carried out using the StatView software package (Abacus Concepts Inc., Berkeley, CA, USA), and differences were considered significant at a p-value $<0.05$.

\section{Results}

LATS2 gene mutation status in Japanese lung cancer patients. We sequenced for the exon 8 of the LATS 2 gene in 178 NSCLC samples. No mutations were found in the 178 patients from the direct sequencing using cDNA samples.

LATS gene methylation statuses in Japanese lung cancer patients. Methylation-specific PCR showed that the LATS1 promoter region was hypermethylated in 95 out of 119 (79.8\%) lung cancers. The methylation status of LATS1 was significantly associated with squamous histology (squamous cell carcinoma, $92.3 \%$ vs. non-squamous cell carcinoma, $73.8 \%$; $=0.0267$ ) and smoking status (never-smoker, $66.7 \%$ vs. smoker, $84.9 \%$; $\mathrm{p}=0.0399)$. However, LATS1 methylation status did not correlate with gender $(\mathrm{p}=0.1872)$, age $(\mathrm{p}=0.8190)$, lymph node 
EGFR metastasis $(\mathrm{p}=0.4880)$ and pathological stages (I vs. II-IV; $\mathrm{p}=0.6470$ ). LATS1 ummethylated patients harbored more EGFR mutations ( $\mathrm{p}=0.0143$ ). LATS1 methylation status did not correlate with patient survival (log-rank test; $\mathrm{p}=0.4109$ ).

The LATS 2 promoter region was hypermethylated in 160 out of 203 (78.8\%) lung cancers (Fig. 1). However, the methylation status revealed no associations with the clinicopathologic characteristics of the lung cancers. The LATS2 methylation status did not correlate with patient survival (log-rank test; $\mathrm{p}=0.4598$ ).

\section{Discussion}

We found that the LATS gene family was hypermethylated in Japanese lung cancers. We did not find correlations between the methylated statuses and gender, pathological stages and survival in Japanese NSCLC. Although the LATS1 methylation status was correlated with smoking status, squamous histology and EGFR mutations, the methylation status of the LATS genes was of limited value in Japanese lung cancers. In addition, we did not find a LATS2 mutation at exon 8, suggesting that an ethnic difference may exist.

The LATS tumor suppressor family has been shown to play an important role in the control of tumor development and the cell cycle $(3-5,18,19)$. Mechanistic studies concerning LATS1 revealed that it might control tumorigenesis by negatively regulating the cell cycle. Ectopic expression of LATS1 in human cancer cell lines leads to the down-regulation of cyclin $\mathrm{A}$ and $\mathrm{B}$ at the protein level (5), and/or inactivation of CDC2 kinase, thereby blocking cells at G2/M and preventing tumor development in nude mice $(4,5)$. Ectopic expression of LATS1 in human tumor cell lines has also been shown to induce apoptosis by up-regulating the level of BAX protein (5) or upregulating caspase-3 activity (4), indicating that LATS1 may also control tumorigenesis by inducing apoptosis. Although it is unclear whether smoking induces the methylation of LATS1, the methylation also occurred more frequently in squamous cell carcinoma. Notably, a chromosomal alteration was frequently noted at chromosome 6q24 (20) where the LATS1 gene is localized (18).

LATS2, also known as KPM (21), is the second mammalian member of the LATS tumor suppressor gene family (22). Human LATS2 has been mapped onto human chromosome 13q11-12 (21), a hot spot (67\%) for loss of heterozygosity in NSCLC (23). LATS2 encodes a putative Ser/Thr protein kinase. The LATS2 protein shares $85 \%$ sequence identify to human LATS1 proteins in the kinase domain $(21,22)$.

LATS2 has a role in the maintenance of mitotic fidelity and genomic stability, since $L A T S^{-/-}$mutant embryonic cells exhibit an increased frequency of cytokinetic defects, accumulation of micronuclei, supernumerary centrosomes and aneuploidy (24,25). LATS2 also functions as an inducer of apoptosis through down-regulation of anti-apoptotic proteins of the Bcl-family (8). More recent findings implicate LATS2 as the key mediator of the G1 tetraploidy checkpoint, while LATS2 translocates into the nucleus by mitotic apparatus dysfunction and inactivates Mdm2 (9). Although downregulation of the LATS2 gene has been reported in several cancers $(10,11)$ including lung cancer $(12)$, in our analysis we did not find any correlation between LATS2 methylation and clinicopathological features. We did not find a LATS2 mutation at exon 8. An ethnic difference between the studies concerning mutant LATS2 may exist.

In conclusion, the LATS2 mutation in Japanese lung cancers appears to be extremely rare, and the methylation status of the LATS genes is of limited value in Japanese lung cancers.

\section{Acknowledgements}

The authors would like to thank Mrs. Tomomi Shibata for her excellent technical assistance. This study was supported by a Grand-in-Aid for Research, Nagoya City University (2006) and Grants-in-Aid for Scientific Research, Japan Society for the Promotion of Science (JSPS) (nos. 21591820 and 21390394).

\section{References}

1. Justice RW, Zilian O, Woods DF, Noll M and Bryant PJ: The Drosophila tumor suppressor gene warts encodes a homolog of human myotonic dystrophy kinase and is required for the control of cell shape and proliferation. Genes Dev 9: 534-546, 1995.

2. Xu T, Wang W, Zhang S, Stewart RA and Yu W: Identifying tumor suppressors in genetic mosaics: the Drosophila lats gene encodes a putative protein kinase. Development 121: 1053-1063, 1995.

3. John MA, Tsao W, Fei X, et al: Mice deficient of Lats1 develop soft-tissue sarcomas, ovarian tumors and pituitary dysfunction. Nat Genet 21: 182-186, 1999.

4. Yang X, Li D, Chen W and Xu T: Human homologue of the Drosophila lats, LATS1, negatively regulates growth by inducing G2/M arrest or apoptosis. Oncogene 20: 6516-6523, 2001.

5. Xia H, Qi H, Li Y, et al: LATS1 tumor suppressor regulates G2/M transition and apoptosis. Oncogene 21: 1233-1241, 2001.

6. Kamikubo Y, Takaori-Kondo A, Uchiyama $\mathrm{T}$ and Hori $\mathrm{T}$ : Inhibition of cell growth by conditional expression of $\mathrm{kpm}$, a human homologue of Drosophila warts/lats tumor suppressor. J Biol Chem 278: 17609-17614, 2003.

7. Li Y, Pei J, Xia H, Ke H, Wang $\mathrm{H}$ and Tao W: Lats2, a putative tumor suppressor, inhibits G1/S transition. Oncogene 22: 4398-4405, 2003.

8. Ke H, Pei J, Ni Z, et al: Putative tumor suppressor Lats2 induces apoptosis through down-regulation of Bcl-2 and $\mathrm{Bcl}-\mathrm{x}(\mathrm{L})$. Exp Cell Res 298: 329-338, 2004.

9. Aylon Y, Michael D, Shumueli A, Yabuta N, Nojima H and Oren M: A positive feedback loop between the p53 and Lats2 tumor suppressors prevents tetraploidization. Genes Dev 20: 2687-2700, 2006.

10. Takahashi Y, Miyoshi Y, Takahata C, et al: Down-regulation of LATS1 and LATS2 mRNA expression by hypermethylation and its association with biologically aggressive phenotype in human breast cancers. Clin Cancer Res 11: 1380-1385, 2005.

11. Jimenez-Velasco A, Roman-Gomez J, Agirre X, et al: Downregulation of the large tumor suppressor 2 (LATS/KPM) gene is associated with poor prognosis in acute lymphoblastic leukemia. Leukemia 19: 2347-2350, 2005.

12. Strazisar M, Mlakar V and Glavac D: LATS2 tumor specific mutations and down-regulation of the gene in non-small cell carcinoma. Lung Cancer 64: 257-262, 2008.

13. Japan Lung Cancer Society, General Rule for Clinical and Pathological Record of Lung Cancer. 5th edition, The Japan Lung Cancer Society 5: 1-177, 1999.

14. Paez JG, Janne PA, Lee JC, et al: EGFR mutations in lung cancer: correlation with clinical response to gefitinib therapy. Science 304: 1497-1500, 2004.

15. Endo K, Konishi A, Sasaki H, et al: Epidermal growth factor receptor gene mutation in non-small cell lung cancer using highly sensitive and fast TaqMan PCR assay. Lung Cancer 50: 375-384, 2005.

16. Sasaki H, Shimizu S, Endo K, et al: EGFR and erbB2 mutation status in Japanese lung cancer patients. Int J Cancer 118: 180-184, 2006.

17. Sasaki H, Endo K, Konishi A, et al: EGFR mutation status in Japanese lung cancer patients: genotyping analysis using LightCycler. Clin Cancer Res 11: 2924-2929, 2005.

18. Nishiyama Y, Hirota T, Morisaki T, et al: A human homolog of Drosophila warts tumor suppressor, h-warts, localized to mitotic apparatus and specifically phosphorylated during mitosis. FEBS Lett 459: 159-165, 1999. 
19. Tao W, Zhang S, Turenchalk GS, et al: Human homologue of the Drosophila melanogaster lats tumor suppressor modulates CDC2 activity. Proc Natl Acad Sci USA 96: 11335-11340, 1999

20. Petersen S, Aninat-Meyer M, Schluns K, Gellert K, Dietel M and Petersen I: Chromosomal alterations in the clonal evolution to the metastatic stage of squamous cell carcinoma of the lung. Br J Cancer 82: 65-73, 2000.

21. Hori T, Takaori-Kondo A, Kamikubo $\mathrm{Y}$ and Uchiyama $\mathrm{T}$ : Molecular cloning of a novel human protein kinase, $\mathrm{kpm}$, that is homologous to warts/lats a Drosophila tumor supressor. Oncogene 19: 3101-3109, 2000.

22. Yabuta N, Fujii T, Copeland NG, et al: Structure, expression and chromosome mapping of LATS2, a mammalian homologue of the Drosophila tumor suppressor gene lats/warts. Genomics 63: 263-270, 2000
23. Girard L, Zochbauer-Muller S, Virmani AK, Gazdar AF and Minna JD: Genome-wide allelotyping of lung cancer identifies new regions of allelic loss, differences between small-cell lung cancer and non-small cell lung cancer, and loci clustering. Cancer Res 60: 4894-4906, 2000.

24. McPherson JP, Tamblyn L, Elia A, et al: Lats $2 / \mathrm{Kpm}$ is required for embryonic development, proliferation control and genomic integrity. EMBO J 23: 3677-3688, 2004.

25. Yabuta N, Okada N, Ito A, et al: Lats2 is an essential mitotic regulator required for the coordination of cell division. J Biol Chem 282: 19259-19271, 2007. 